animals from a selected area may produce valuable results, both as regards knowledge of the habits of the fly, and as to the extent to which the infectivity of the fly and subsequently the infection of man or stock is derived from wild animals. The result of this experiment cannot be confidently anticipated, but, nevertheless, the committee think there is sufficient to justify an expectation of useful results and recommend that if a suitable locality can be found where an experiment can be carried out at a reasonable cost, it should be undertaken.

\section{RECENT STUDIES OF THE ATMOSPHERE.1}

THE German Meteorological Society offered a prize for the best essay on the results of the International Kite and Balloon ascents, and the prize was won by Mr. Gold in I9I 2 by the memoir which is now published by the Meteorological Office. The results mostly refer to ascents which took place prior to December, I909, but in the case of some stations observations are included up to November, I9I I. From an exhaustive consideration of the temperature in the free air and its relation to pressure at sea-level, geographical position, and season, it appears that in Europe August is, in general, the warmest month in the troposphere, and March the coldest, except close to the surface; thus, the temperature lag is greater for the minimum than for the maximum, which, as is pointed out in the memoir, is to be expected, for convection can carry warmth upwards, but not cold. It has become apparent from the study of the upper air that a cyclone is colder than an anticyclone, and this is borne out by Mr. Gold's figures; he finds that a cyclone is colder than an anticyclone up to ten kilometres, that is, up to the level of the stratosphere.

The height at which the stratosphere is found, and its temperature, are known to vary with the surface pressure; the higher the pressure the higher is the lower limit of the stratosphere and the lower the temperature of the layer. Mr. Gold has investigated this point in detail and gives diagrams showing the changes in the stratosphere in height and in temperature through areas of high and low pressure, both in winter and summer. The places where sounding balloons fall show that the general drift of the wind over Europe is from the north-west in the upper air. Balloons sent up in easterly winds usually fall to the east of the starting place in winter, showing that at this season an easterly current is shallow, the pressure gradient above being reversed by the gradient of temperature from south to north. Mr. Gold discusses many questions of the winds and the dynamics of the atmosphere, but it is impossible

1 Geophvsical Memoirs (Meteorological Office) :-

No. 5. The International Kite and Balloon Ascents, By Ernest Gold. (rgr3.) Price is. 6d.

No. 6. The Free Atmosphere in the Region of the British Isles (Third Report). The Calibration of the Balloon Instruments and the Reading of the Traces. By W. H. Dines, F.R.S. (I9r4.) Price id.

No. 7. A Comparison of the Electrical Conditions of the Atmosphere at Kew and Eskdalemuir. By Gordon Dobson. (Igr4) Price 8d.

No. 8. Lag in Marine Barometers on Land and Sea. By Dr. Charles Chiree, F.R.S. (1914.) Price $4 d$.

$$
\text { NO. } 2336 \text {, VOL. 93] }
$$

in a short notice even to indicate every point in the work; it should be read by all interested in dynamical meteorology.

Almost all the observations in the upper air in this country are made with Mr. W. H. Dines's light meteorograph. In Geophysical Memoir, No. 6, Mr. Dines describes very fully the method of calibrating, preparing the instrument for the ascent, and working up the trace. With these instructions and those given in a former publication of the Meteorological Office (M. O. 202) an observer should be able to use the instrument to full advantage

Electrical observations of the atmosphere at the new observatory at Eskdalemuir are discussed by Mr. Dobson in the Geophysical Memoirs, and compared with those at Kew. Conditions differ in several respects, being far more disturbed at the northern station. The diurnal curves of the potential gradient for the two stations are similar during the winter, but differ markedly in the summer; at this season the potential at Eskdalemuir is high at night and begins to fall in the early morning when it is rising to a maximum at Kew. The mean absolute value of the potential gradient is always higher at Kew than at Eskdalemuir, which Mr. Dobson attributes chiefly to the abnormally low conductivity of the air at Kew. The small and uncertain difference in the number of ions between summer and winter at Eskdalemuir is remarkable. The station has not been long established, and the account given in this memoir will, no doubt, be amplified when a longer series of observations from Eskdalemuir is available.

The constriction in the tube of the marine barometer, made to avoid oscillations of the mercury, causes a lag which is discussed by Dr. Chree in No. 8 of the Geophysical Memoirs. The theory was considered by Stokes, who found that the marine barometer had a certain "lagging time." If the sluggishness were due to the constriction alone the lag should be too small to affect readings in practice. But Dr. Chree has investigated the problem by the consideration of the readings of a number of barometers tested at Kew, and finds the lag to be considerably greater than according to Stokes's formula. Further observations with the same result were made with two barometers which were subsequently put on board ship, and read every four hours by the ship's officers during a number of voyages across the Atlantic; the lag at sea was found to be much less than on land, and was almost entirely confined to cases where the barometer was "pumping." No explanation is put forward to account for "the extraordinary difference between land and sea results." Dr. Chree is not of opinion that it can be explained by uncertainties of reading at sea. Further observations are hinted at. and it is certainly desirable to find out why on land the lag should be "enormously greater" than given by Stokes's formula, while at sea it is "exceedingly small." 